\title{
Roles of the Amygdala and Basal Forebrain in Defense: a Reply to Luyck Et al. and Implications for Defensive Action
}

\author{
Floris Klumpers $^{1,2}$ (D) Marijn C. W. Kroes ${ }^{3}$
}

Received: 6 December 2018 / Accepted: 26 February 2019 / Published online: 19 March 2019

(C) The Author(s) 2019

\begin{abstract}
The commentary by Luyck and colleagues on our paper provides many stimulating viewpoints and interpretations of our original study on dissociable responses in the amygdala and bed nucleus of the stria terminalis in threat processing. Here, we reply to some of the points raised and while agreeing with most of the comments also provide some alternative viewpoints. We end by putting forward a research agenda for how to further investigate the roles of these regions in threat processing, with an emphasis on studying their roles in defensive action.
\end{abstract}

Keywords Anxiety $\cdot$ Fear $\cdot$ Amygdala $\cdot$ Bed nucleus of the stria terminalis $\cdot$ Avoidance $\cdot$ Anxiety disorders $\cdot$ Threat $\cdot$ Defensive $\cdot$ Defensive action $\cdot$ Defensive reaction $\cdot$ Threat avoidance $\cdot$ Threat imminence $\cdot$ Nucleus accumbens $\cdot$ Translational

We thank Luyck et al. (2018) for a thoughtful commentary and interesting discussion of the implications of our findings (Klumpers et al., 2017). Their commentary stimulated our thinking, and therefore below we respond to some of the points raised. In addition, we propose further suggestions for how the field might proceed in defining the roles of the amygdala, bed nucleus of the stria terminalis (BNST), and other basal forebrain regions in threat processing.

In our original publication (Klumpers et al., 2017), we reported that neural activity shifted from the BNST to the amygdala when moving from a state of threat anticipation to confrontation with an aversive outcome. Interestingly, only participants who experienced greater childhood maltreatment showed amygdala activation during shock anticipation, without change in BNST activation. Luyck and colleagues rightly caution against over-interpreting the clinical implications of our findings. A critical next step, indeed, for verifying whether

Floris Klumpers

F.Klumpers@donders.ru.nl

1 Experimental Psychopathology and Treatment Section, Behavioural Science Institute, Radboud University, Nijmegen, The Netherlands

2 Donders Institute for Brain, Cognition and Behaviour, Radboud University, Nijmegen, The Netherlands

3 Donders Institute for Brain, Cognition and Behaviour, Radboud University Nijmegen Medical Center, Nijmegen, The Netherlands the balance between BNST and amygdala activation during threat anticipation contributes to psychopathology is testing a patient population. Regardless, we believe our findings refine the fundamental roles of the BNST and amygdala in threat processing and can inform hypotheses and guide analyses of such future patient studies. Direct comparison between the amygdala and BNST responses to different levels of threat imminence could be particularly informative. Clinical models of stress and anxiety have generally focused on the amygdala, yet many findings also implicate the BNST in anxious psychopathology (Lebow \& Chen, 2016). This raises the question whether the amygdala and BNST have a similar contribution to clinical symptoms or if specific aberrations in these regions can lead to unique symptom profiles.

A second point in the commentary considers possible interpretations of those outcomes that appeared discordant in our two large neuroimaging samples. For example, as correctly pointed out by the authors, considerably fewer regions were significantly activated in sample 2 compared to sample 1 . Luyck and colleagues link this discrepancy to the difference in temporal unpredictability of the aversive outcome (shocks), which was greater in the second sample. While this is an interesting suggestion, we would like to point out that interpretation of the differences in results between our two samples lacks solid ground without a formal statistical test demonstrating that numerical differences in the mean group response are robust relative to the variance observed within each group. A direct comparison of amygdala and BNST responses to threat anticipation 
and confrontation with an aversive outcome between our two samples failed to reach significance (all $p$-values $>.09$ ). While Luyck and colleagues' interpretation rests on a solid theoretical framework linking the BNST to temporal unpredictability (Goode \& Maren, 2017) and may well be correct, we believe such interpretations of our data may be premature, even regardless of statistical robustness. This is because the two samples differed in a wide range of characteristics other than temporal unpredictability. Most notably, the experiment for the first sample was (I) shorter and contained fewer trials, (II) was scanned at a lower temporal resolution at an MR scanner from a different manufacturer (Philips vs Siemens) and (III) the samples were different that the first sample contained fewer subjects (70 vs 108 ; leading to differences in statistical power) and consisted only of males (vs. $70 \%$ females in sample 2). While these factors were not of direct interest to our study, they all potentially contributed to differences in results between samples. Therefore, while the converging findings across our two independent samples were robust regardless of these different experimental parameters and therefore more convincing, interpretations regarding differences in results between our samples rest on limited evidentiary value.

Luyck et al. also highlight that our results are not a one-toone match with models derived from years of rodent literature, where the amygdala has been posited as important for particularly post-encounter phases and the BNST might be involved in pre-encounter phases where threat is uncertain. We fully agree and particularly support their suggestion for an important distinction between human and rodent work in terms of the level of threat. For ethical reasons, threat levels in human studies are limited compared to rodent studies. We propose that experimental conditions of threat anticipation in humans may thus be shifted down on the threat imminence continuum compared to similar studies in rodents. This might explain the inconsistent amygdala activity in humans when threat is distant while observing clear activation of the BNST, even with short cue durations (Klumpers et al., 2017; Fullana et al., 2016; Mechias et al., 2010; Fox \& Shackman, 2019).

We would like to add an additional explanation for the apparent discrepancy in amygdala and BNST functioning between our findings in humans and those in the rodent literature. One proposed (core) function of emotions is to invigorate the propensity of appropriate behavioral responses (Frijda, 1986; Barrett, 2017). When threat appears at a distance, animals may reduce foraging behaviors and try to stay clear of danger. At the same time the inherent uncertainty about threat can also create an urge to explore and further assess risk. The latter requires staying in contact with the potential threat (e.g., visually) and sometimes even approaching it. When threat comes near, animals may stop all motion, and passively or actively try to avoid threat. At close confrontation with a threat, animals may flee or fight. The exact appropriate behavioral responses will thus dependent on the imminence of threat but also on the specific species confronted with threat. Many

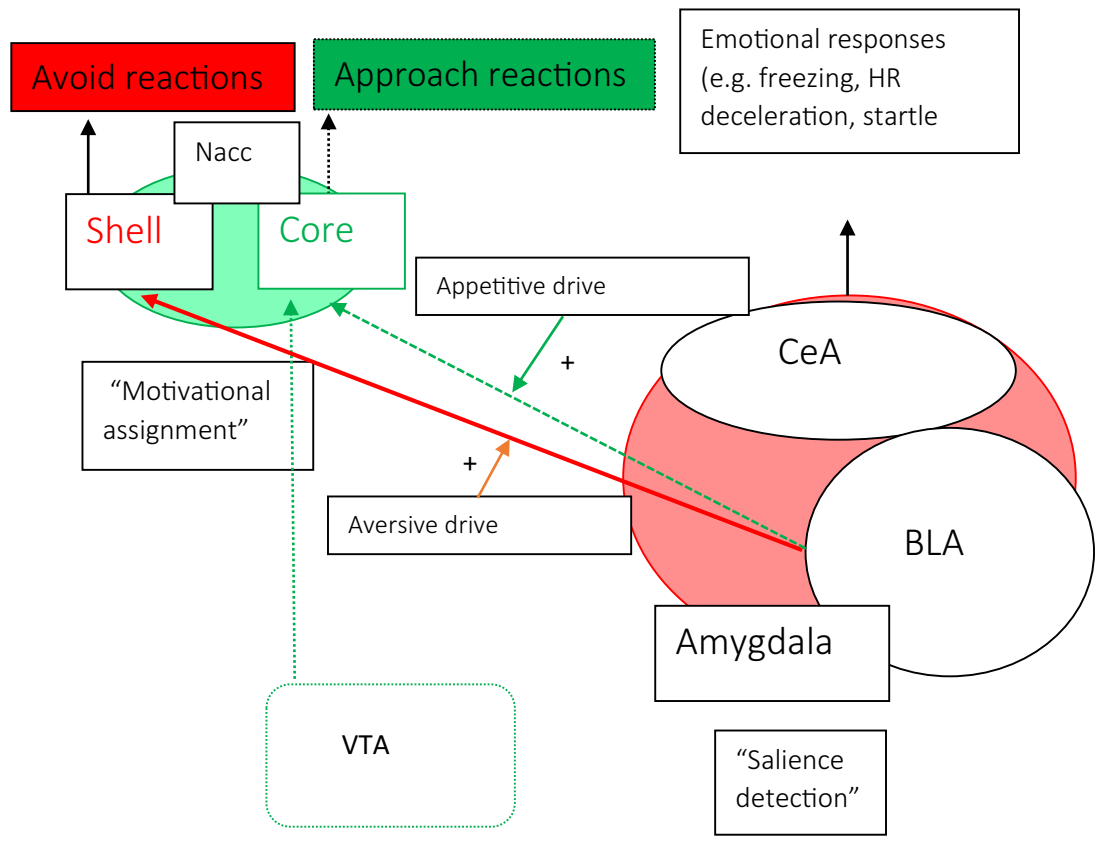

Fig. 1 A neural model for the integration of threat and reward in costly avoidance decision making. The Amygdala and NAcc each have a role in driving both approach and avoid behavior (Gentry et al., 2016; Hamel et al., 2017; Schlund \& Cataldo, 2010). However, evidence from (pharmacological) lesion and stimulation studies in rodents indicates a relative importance for the BLA in driving avoid responses (Choi \& Kim, 2010; Duque-Wilckens et al., 2018; Burgos-Robles et al., 2017;
Terburg et al., 2018) and a relative importance for the NAcc (core) in approach responses (Hamel et al., 2017; Nachev et al., 2015). One explanation is that in absence of BLA input reward-related inputs from the ventral tegmental area (VTA) continue to drive approach via the NAcc (Cisneros-Franco \& de Villers-Sidani, 2018). This model, however, is still sorely lacking a role for the BNST, which has strong interconnections to both the amygdala and NAcc 
species-specific responses along the threat imminence continuum are reactions (e.g. running, jumping, flying, burrowing), which may require distinct neural mechanisms to deal with the threat. We, however, still know little about these speciesspecific threat-reactions and the differences in the underlying neurocircuitry. Most threat studies in rodents are conducted in small test environments limiting the behaviors animals will express. Perhaps even more problematic, human participants in threat studies are generally instructed to refrain from any movements while constantly looking at the screen to optimize psychophysiological recording (e.g. startle electromyography, galvanic skin conductance responses and fMRI). Restricting behavioral responses in threat experiments thus provides a limited assay of threat behaviour (Gentry et al., 2016; Hamel et al., 2017; LeDoux et al., 2017; Beckers et al., 2013; Cain, 2019) and as a result instrumental threat-related behaviors in rodents and humans remain relatively understudied (LeDoux et al., 2017) notwithstanding recent progress (Aupperle et al., 2015; Schlund et al., 2016; Boeke et al., 2017; Moscarello \& LeDoux, 2013; Ramirez et al., 2015). In our study we also did not probe defensive reactions such as approach and avoid tendencies. An additional explanation for differences between our findings and those of studies in rodents may thus be the degree to which similar and distinct neural mechanisms for threat reactions are invigorated. Increased understanding of species-specific threat reactions could thus help to explain differences in observations between threat studies in rodents and humans.

Philosophers, psychologists and behavioral neuroscientists alike regard conflict between approach and avoidance motivational tendencies as central to anxiety (Kierkegaard, 1980; Blanchard et al., 2011; McNaughton \& Corr, 2004; Corr, 2013; Kirlic et al., 2017). Understanding the neural mechanisms of instrumental threat-related approach and avoidance behaviors and their conflict is therefore critical to understand neural circuits driving anxiety and especially pathological anxiety because excessive avoidance is a hallmark symptom in stress- and anxiety disorders (Craske \& Stein, 2016). An interesting perspective for future research is, therefore, to investigate potentially distinct roles of the amygdala and BNST in threat-actions. Current neurobiological models of avoidance are based largely on threat avoidance learning experiments with rodents and highlight the importance of amygdala connections to the ventral striatum, particularly the nucleus accumbens. Human and rodent decision-making paradigms have identified a similar pathway underlying instrumental approach reactions and the ventral striatum has long been implicated in appetitive processing (Fig. 1). Distinct amygdalanucleus accumbens pathways thus appear involved in both approach and avoidance reactions of rewarding and aversive outcomes. The nucleus accumbens borders the BNST in both rodents and primates and the regions have tight interconnections. Evidence implicates the BNST in avoidance (Duque-
Wilckens et al., 2018) consistent with its strong connections to striatal and motor regions (Klumpers et al., 2017). Indeed functionally defined sub-regions of the BNST have recently been implicated in driving oppositely-valenced approach and avoid reactions via their connections to the hypothalamus (Giardino et al., 2018). However, to what extent the BNST's role may be distinct from the amygdala is unclear, potentially because most threat-avoidance studies take place on the proximal end of the threat imminence continuum (Cain, 2019). We thus call for additional research on the role of the BNST and amygdala in driving behavioral reactions along the entire threat imminence continuum.

Finally, as described above, conflicting motivational tendencies might be central to anxiety and therefore it will be highly informative for a better understanding of clinically relevant mechanisms to include conditions of conflicting motivational tendencies in research on defensive-reactions. As opposed to the majority of previous work on defensive reactions, daily life rarely involves situations with unambiguously optimal behavioral reactions and including these conflicting motivational conditions in threat studies would thus allow more accurate modelling of pathological avoidance (Pittig et al., 2018; Krypotos et al., 2018). Illustrating this point, threat avoidance per se is not pathological and might even be a healthy and efficient strategy (Boeke et al., 2017). Pathological anxiety, however, is characterized by avoidance under ambiguous conditions that is persistent even in the face of high costs such as social isolation and functional impairment (Pittig et al., 2018). Thus, studies investigating the role of the amygdala and BNST using paradigms that allow more active behaviors and include conditions of approach/avoidance conflict are highly anticipated.

Acknowledgements The writing of this article has been approved by Prof. Guillen Fernandez \& Dr. Johanna Baas (co-authors on the original paper under commentary).

Open Access This article is distributed under the terms of the Creative Commons Attribution 4.0 International License (http:// creativecommons.org/licenses/by/4.0/), which permits unrestricted use, distribution, and reproduction in any medium, provided you give appropriate credit to the original author(s) and the source, provide a link to the Creative Commons license, and indicate if changes were made.

\section{References}

Aupperle, R. L., Melrose, A. J., Francisco, A., Paulus, M. P., \& Stein, M. B. (2015). Neural substrates of approach-avoidance conflict decision-making. Human Brain Mapping, 36(2), 449-462. https://doi. org $/ 10.1002 / \mathrm{hbm} .22639$

Barrett, L. F. (2017). The theory of constructed emotion: An active inference account of interoception and categorization. Social Cognitive and Affective Neuroscience, 12(11), 1833. https://doi.org/10.1093/ scan/nsx 060

Beckers, T., Krypotos, A. M., Boddez, Y., Effting, M., \& Kindt, M. (2013). What's wrong with fear conditioning? Biological 
Psychology, 92(1), 90-96. https://doi.org/10.1016/j.biopsycho. 2011.12.015

Blanchard, D. C., Griebel, G., Pobbe, R., \& Blanchard, R. J. (2011). Risk assessment as an evolved threat detection and analysis process. Neuroscience and Biobehavioral Reviews, 35(4), 991-998. https:// doi.org/10.1016/j.neubiorev.2010.10.016

Boeke, E. A., Moscarello, J. M., LeDoux, J. E., Phelps, E. A., \& Hartley, C. A. (2017). Active avoidance: Neural mechanisms and attenuation of Pavlovian conditioned responding. The Journal of Neuroscience, 37(18), 4808-4818. https://doi.org/10.1523/JNEUROSCI.3261-16. 2017

Burgos-Robles, A., et al. (2017). Amygdala inputs to prefrontal cortex guide behavior amid conflicting cues of reward and punishment. Nature Neuroscience, 20, 824. https://doi.org/10.1038/nn.4553, https://www.nature.com/articles/nn.4553\#supplementaryinformation. Accessed 1 Dec 2018.

Cain, C. K. (2019). Avoidance problems reconsidered. Current Opinion in Behavioral Sciences, 26(9-17), 9-17. https://doi.org/10.1016/j. cobeha.2018.09.002

Choi, J. S., \& Kim, J. J. (2010). Amygdala regulates risk of predation in rats foraging in a dynamic fear environment. Proceedings of the National Academy of Sciences of the United States of America, 107(50), 21773-21777. https://doi.org/10.1073/pnas.1010079108

Cisneros-Franco, J. M. \& de Villers-Sidani, E. (2018) Bidirectional Control of Risk-Seeking Behavior by the Basolateral Amygdala. eNeuro 5, ENEURO.0168-0118.2018, https://doi.org/10.1523/ ENEURO.0168-18.2018 (2018).

Corr, P. J. (2013). Approach and avoidance behaviour: Multiple systems and their interactions. Emotion Review, 5(3), 285-290. https://doi. org/10.1177/1754073913477507

Craske, M. G., \& Stein, M. B. (2016). Anxiety. Lancet, 388(10063), 3048-3059. https://doi.org/10.1016/S0140-6736(16)30381-6

Duque-Wilckens, N., Steinman, M. Q., Busnelli, M., Chini, B., Yokoyama, S., Pham, M., ... Trainor, B. C. (2018). Oxytocin receptors in the anteromedial bed nucleus of the Stria terminalis promote stress-induced social avoidance in female California mice. Biological Psychiatry, 83(3), 203-213. https://doi.org/10.1016/j. biopsych.2017.08.024

Fox, A. S., \& Shackman, A. J. (2019). The central extended amygdala in fear and anxiety: Closing the gap between mechanistic and neuroimaging research. Neuroscience Letters, 693, 58-67. https://doi.org/ 10.1016/j.neulet.2017.11.056

Frijda, N. H. (1986) The emotions. (Cambridge University Press, 1986). Fullana, M. A., Harrison, B. J., Soriano-Mas, C., Vervliet, B., Cardoner, N., Àvila-Parcet, A., \& Radua, J. (2016). Neural signatures of human fear conditioning: An updated and extended meta-analysis of fMRI studies. Molecular Psychiatry, 21(4), 500-508. https://doi. org/10.1038/mp.2015.88

Gentry, R. N., Lee, B., \& Roesch, M. R. (2016). Phasic dopamine release in the rat nucleus accumbens predicts approach and avoidance performance. Nature Communications, 7(1), 13154. https://doi.org/10. 1038/ncomms13154. https://www.nature.com/articles/ ncomms13154\#supplementary-information. Accessed 1 Dec 2018.

Giardino, W. J., Eban-Rothschild, A., Christoffel, D. J., Li, S. B., Malenka, R. C., \& de Lecea, L. (2018). Parallel circuits from the bed nuclei of stria terminalis to the lateral hypothalamus drive opposing emotional states. Nature Neuroscience, 21(8), 1084-1095. https://doi.org/10.1038/s41593-018-0198-x

Goode, T. D., \& Maren, S. (2017). Role of the bed nucleus of the stria terminalis in aversive learning and memory. Learning \& Memory, 24(9), 480-491. https://doi.org/10.1101/lm.044206.116

Hamel, L., Thangarasa, T., Samadi, O., \& Ito, R. (2017). Caudal nucleus Accumbens Core is critical in the regulation of Cue-elicited approach-avoidance decisions. eneuro, 4(1), ENEURO.0330ENEU16.2017.
Kierkegaard, S. (1980) The concept of anxiety : a simple psychologically orienting deliberation on the dogmatic issue of hereditary sin. (Princeton, N.J. : Princeton University press, [1980] (01980).

Kirlic, N., Young, J., \& Aupperle, R. L. (2017). Animal to human translational paradigms relevant for approach avoidance conflict decision making. Behaviour Research and Therapy, 96, 14-29. https://doi. org/10.1016/j.brat.2017.04.010

Klumpers, F., Kroes, M. C. W., Baas, J., \& Fernández, G. (2017). How human amygdala and bed nucleus of the stria terminalis may drive distinct defensive responses. The Journal of Neuroscience, 37(40), 9645-9656. https://doi.org/10.1523/jneurosci.3830-16.2017

Krypotos, A.-M., Vervliet, B., \& Engelhard, I. M. (2018). The validity of human avoidance paradigms. Behaviour Research and Therapy, 111, 99-105. https://doi.org/10.1016/j.brat.2018.10.011

Lebow, M. A., \& Chen, A. (2016). Overshadowed by the amygdala: The bed nucleus of the stria terminalis emerges as key to psychiatric disorders. Molecular Psychiatry, 21(4), 450-463. https://doi.org/ 10.1038/mp.2016.1

LeDoux, J. E., Moscarello, J., Sears, R., \& Campese, V. (2017). The birth, death and resurrection of avoidance: A reconceptualization of a troubled paradigm. Molecular Psychiatry, 22(1), 24-36. https:// doi.org/10.1038/mp.2016.166

Luyck, K., Goode, T. D., Lee Masson, H., \& Luyten, L. (2018). Distinct activity patterns of the human bed nucleus of the Stria terminalis and amygdala during fear learning. Neuropsychology Review. https:// doi.org/10.1007/s11065-018-9383-7

McNaughton, N. \& Corr, P. J. A two-dimensional neuropsychology of defense: Fear/anxiety and defensive distance. Neuroscience and Biobehavioral Reviews 28, 285-305, https://doi.org/10.1016/j. neubiorev.2004.03.005S0149763404000326 [pii] (2004)., 2004

Mechias, M. L., Etkin, A., \& Kalisch, R. (2010). A meta-analysis of instructed fear studies: Implications for conscious appraisal of threat. Neuroimage, 49(2), 1760-1768. https://doi.org/10.1016/j. neuroimage.2009.09.040

Moscarello, J. M., \& LeDoux, J. E. (2013). Active avoidance learning requires prefrontal suppression of amygdala-mediated defensive reactions. The Journal of Neuroscience, 33(9), 3815-3823. https://doi. org/10.1523/JNEUROSCI.2596-12.2013

Nachev, P., Lopez-Sosa, F., Gonzalez-Rosa, J. J., Galarza, A., Avecillas, J., Pineda-Pardo, J. A., ... Strange, B. (2015). Dynamic risk control by human nucleus accumbens. Brain, 138(12), 3496-3502. https:// doi.org/10.1093/brain/awv285

Pittig, A., Treanor, M., LeBeau, R. T., \& Craske, M. G. (2018). The role of associative fear and avoidance learning in anxiety disorders: Gaps and directions for future research. Neuroscience and Biobehavioral Reviews, 88, 117-140. https://doi.org/10.1016/j.neubiorev.2018.03.015

Ramirez, F., Moscarello, J. M., LeDoux, J. E., \& Sears, R. M. (2015). Active avoidance requires a serial basal amygdala to nucleus accumbens shell circuit. The Journal of Neuroscience, 35(8), 3470-3477. https://doi.org/10.1523/JNEUROSCI.1331-14.2015

Schlund, M. W., \& Cataldo, M. F. (2010). Amygdala involvement in human avoidance, escape and approach behavior. Neuroimage, 53(2), 769-776. https://doi.org/10.1016/j.neuroimage.2010.06.058

Schlund, M. W., Brewer, A. T., Magee, S. K., Richman, D. M., Solomon, S., Ludlum, M. D., \& Dymond, S. (2016). The tipping point: Value differences and parallel dorsal-ventral frontal circuits gating human approach-avoidance behavior. Neuroimage, 136, 94-105. https:// doi.org/10.1016/j.neuroimage.2016.04.070

Terburg, D., Scheggia, D., Triana del Rio, R., Klumpers, F., Ciobanu, A. C., Morgan, B., ... van Honk, J. (2018). The basolateral amygdala is essential for rapid escape: A human and rodent study. Cell, 175(3), 723-735 e716. https://doi.org/10.1016/j.cell.2018.09.028

Publisher's Note Springer Nature remains neutral with regard to jurisdictional claims in published maps and institutional affiliations. 